\title{
A porous 3D-RGO@MWCNT hybrid material as Li-S battery cathode
}

\author{
Yongguang Zhang ${ }^{1}$, Jun Ren ${ }^{1}$, Yan Zhao ${ }^{* 1}$, Taizhe Tan ${ }^{2}$, Fuxing Yin ${ }^{1}$ \\ and Yichao Wang ${ }^{*}$
}

\section{Full Research Paper}

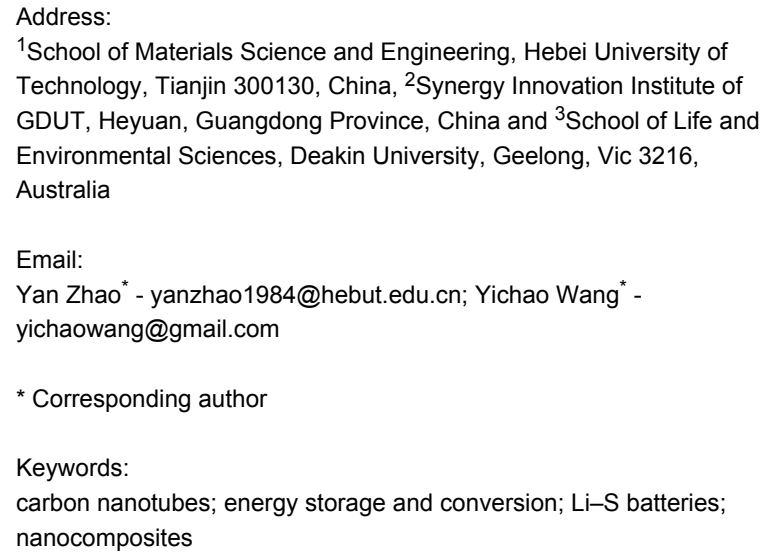

${ }^{1}$ School of Materials Science and Engineering, Hebei University of Technology, Tianjin 300130, China, ${ }^{2}$ Synergy Innovation Institute of GDUT, Heyuan, Guangdong Province, China and ${ }^{3}$ School of Life and Environmental Sciences, Deakin University, Geelong, Vic 3216, Australia

Email:

Yan Zhao* - yanzhao1984@hebut.edu.cn; Yichao Wang * yichaowang@gmail.com

* Corresponding author

\section{Keywords:}

carbon nanotubes; energy storage and conversion; Li-S batteries; nanocomposites

Beilstein J. Nanotechnol. 2019, 10, 514-521.

doi:10.3762/bjnano. 10.52

Received: 01 November 2018

Accepted: 11 February 2019

Published: 21 February 2019

This article is part of the thematic issue "Low-dimensional materials and systems".

Guest Editor: S. Walia

(C) 2019 Zhang et al.; licensee Beilstein-Institut.

License and terms: see end of document.

\begin{abstract}
In this work, a unique three-dimensional (3D) structured carbon-based composite was synthesized. In the composite, multiwalled carbon nanotubes (MWCNT) form a lattice matrix in which porous spherical reduced graphene oxide (RGO) completes the 3D structure. When used in $\mathrm{Li}-\mathrm{S}$ batteries, the 3D porous lattice matrix not only accommodates a high content of sulfur, but also induces a confinement effect towards polysulfide, and thereby reduces the "shuttle effect". The as-prepared S-3D-RGO@MWCNT composite delivers an initial specific capacity of $1102 \mathrm{mAh} \cdot \mathrm{g}^{-1}$. After 200 charging/discharge cycles, a capacity of $805 \mathrm{mAh} \cdot \mathrm{g}^{-1}$ and a coulombic efficiency of $98 \%$ were maintained, implying the shuttle effect was greatly suppressed by the composite matrix. In addition, the S-3D-RGO@MWCNT composite also exhibits an excellent rate capability.
\end{abstract}

\section{Introduction}

$\mathrm{Li}-\mathrm{S}$ batteries are notable for their high theoretical specific capacity $\left(1675 \mathrm{mAh} \cdot \mathrm{g}^{-1}\right)$ and energy density $\left(2600 \mathrm{Wh} \cdot \mathrm{kg}^{-1}\right)$. Sulfur is an abundant element, enabling $\mathrm{Li}-\mathrm{S}$ batteries to be highly competitive among the various battery technologies. The actual application of $\mathrm{Li}-\mathrm{S}$ batteries, however, is hindered by several challenges, i.e., i) the poor conductivity of sulfur and ii) the "shuttle effect" of polysulfides $\left(\mathrm{Li}_{2} \mathrm{~S}_{x}, 4<x \leq 8\right)$ [1-4]. To achieve a high specific capacity, a sulfur cathode with high electrical conductivity and high sulfur loading is necessary. The shuttle effect will result in rapid fading of the capacity and coulombic efficiency during the cycling process. Therefore, the development of a sulfur cathode that can "withhold" sulfur and reduce the shuttle effect, together with a high conductivity and sulfur loading is essential for the practical implementation of Li-S batteries [5-7].

To overcome the above-mentioned challenges in Li-S batteries, many strategies have been proposed [8-12]. For example, metal 
oxides, such as $\mathrm{TiO}_{2}, \mathrm{ZnO}, \mathrm{MnO}_{2}$, and $\mathrm{SiO}_{2}$, were reported to provide active sites for strong $\mathrm{S}-$ metal bonding that have been reported to suppress the shuttle effect in polysulfides [13-16]. Moreover, designing metal oxides into various unique morphologies, e.g., hollow structures, can also provide a physical (or structural) confinement for sulfur [17]. Metal-oxide materials, however, have a major drawback, i.e., their electronic conductivity is very low $[16,18]$. To improve the conductivity of the sulfur cathode, it was typically composited with carbon materials [19-23]. Moreover, the high surface area of the carbon substrate was beneficial for a higher sulfur loading [24,25]. Since sulfur is the major active ingredient in the $\mathrm{Li}-\mathrm{S}$ cathode, adding more non-sulfur components, such as metal oxides, in the cathode will result in a lower specific capacity.

Therefore, the present study will focus on the development of a pure carbon material for the $\mathrm{Li}-\mathrm{S}$ cathode. It was believed that a carbon-based material network with specific morphology will not only allow for a high sulfur loading but will also provide both the chemical and physical restraints on the polysulfide shuttle effect. In the previous report, we synthesized porous 3D reduced graphene oxide (3D-RGO), showing a reversible capacity of $790 \mathrm{mAh} \cdot \mathrm{g}^{-1}$ (at $0.2 \mathrm{C}$ ) after 200 cycles [26]. It has been reported that three-dimensional carbon nanotubes/ graphene-sulfur (3DCGS) is an excellent cathode template, revealing a final capacity of $975 \mathrm{mAh} \cdot \mathrm{g}^{-1}$ after 200 cycles [24]. Carbon nanotubes (CNTs) can be used to adjust structure and density of the pores of the composite while improving the electrical conductivity. Following such a strategy, we developed a unique three-dimensional structured carbon-based composite material, referred to as 3D-RGO@MWCNT. Multiwalled carbon nanotubes (MWCNTs) form a lattice network for the composite that is supported by porous spherical reduced graphene oxide (RGO). Furthermore, the functional groups on RGO provide bonding sites for the active sulfur material. The 3D porous carbon structure enabled high sulfur loading and confined the sulfur within the 3D MWCNT network and the porous spherical RGO. Moreover, such a 3D structure can buffer the volume expansion/shrinkage of the sulfur cathode during charge and discharge cycles. Lastly, the electrochemical performance of the resulting S-3D-RGO@MWCNT cathode was evaluated in $\mathrm{Li}-\mathrm{S}$ batteries.

\section{Results and Discussion}

The synthesis of the 3D-RGO@MWCNT composite is illustrated in Figure 1, highlighting the 3D porous RGO structure and the MWCNT lattice matrix. The SEM images confirmed that the precursor composite, RGO@MWCNT@ $\mathrm{SiO}_{2}$, contained 200-300 $\mathrm{nm} \mathrm{SiO}$ particles that were successfully encased by RGO and MWCNTs (Figure 2a). After HF etching, a 3D-RGO@MWCNT was obtained (Figure 2b,c). The porous spherical indents (ca. $200 \mathrm{~nm}$ ) remained after the removal of $\mathrm{SiO}_{2}$ (Figure 3a). Furthermore, after sulfur loading, both SEM (Figure 2d) and TEM (Figure 3b) images revealed that the structure remained in the resulting S-3D-RGO@MWCNT composite. The EDS elemental mapping validated the successful and uniform loading of sulfur into the composite (Figure 2e and Figure 3d). The 3D structure provided: i) higher usable surface area for a higher sulfur loading, ii) empty spaces between the pores and the lattice matrix to reduce the shuttle effect by acting as a lithium polysulfide reservoir, and iii) additional empty spaces to buffer the volume expansion/shrinkage in the charge and discharge processes enhancing the cycling performance of the battery. The electrochemical performance of the S-3DRGO@MWCNT composite will be discussed later in the electrochemical analysis.

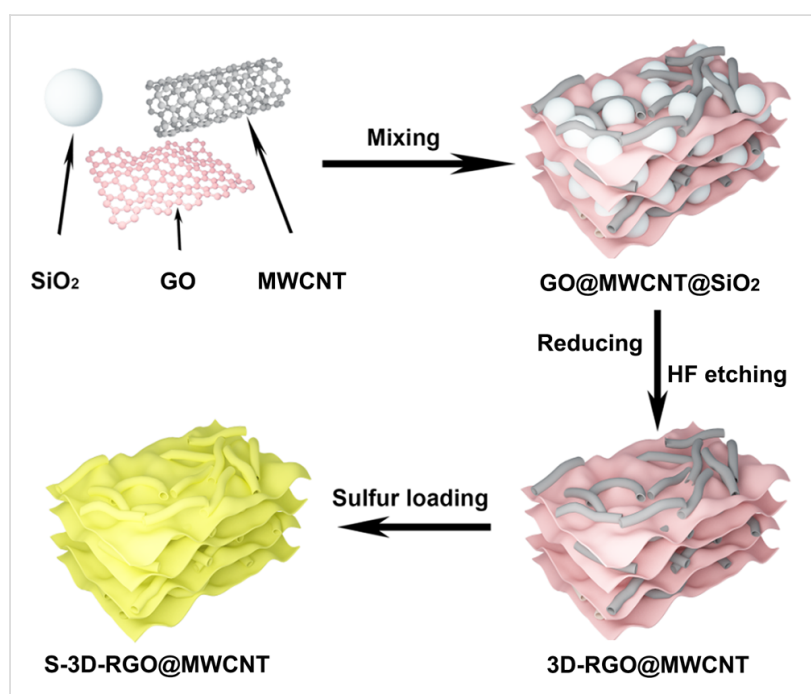

Figure 1: Synthesis of S-3D-RGO@MWCNT.

Figure 4a presents the XRD patterns for pure $S$, 3D-RGO@MWCNT and the S-3D-RGO@MWCNT composite. The XRD pattern of 3D-RGO@MWCNT exhibits two broad characteristic peaks of RGO at around $22^{\circ}$ and $43^{\circ}$. Moreover, a diffraction peak around $26^{\circ}$ for 3D-RGO@MWCNT corresponds to the MWCNTs. In the XRD pattern of S-3DRGO@MWCNT, the major characteristic peaks of crystalline sulfur are observed, which further confirm the preservation of crystalline sulfur in the composite after adding sulfur. The Raman spectra demonstrates that the ratio $I_{\mathrm{D}} / I_{\mathrm{G}}$ decreased from 1.12 in 3D-RGO@MWCNT to 1.04 in S-3D-RGO@MWCNT (Figure 4b), implying that the defects in 3D-RGO@MWCNT were filled or occupied by sulfur [3]. This is also supported by the C 1s XPS pattern of 3D-RGO@MWCNT, in which a $\mathrm{C}-\mathrm{S}$ bonding state $(285.4 \mathrm{eV})$ is observed (Figure $4 \mathrm{~d})$. The $\mathrm{O}-\mathrm{C}=\mathrm{O}$ $(288.8 \mathrm{eV}), \mathrm{C}=\mathrm{O}(287.2 \mathrm{eV})$ and $\mathrm{C}-\mathrm{O}(286.3 \mathrm{eV})$ peaks in the $\mathrm{C} 1 \mathrm{~s}$ pattern confirm the oxide nature of RGO sheets. In addi- 

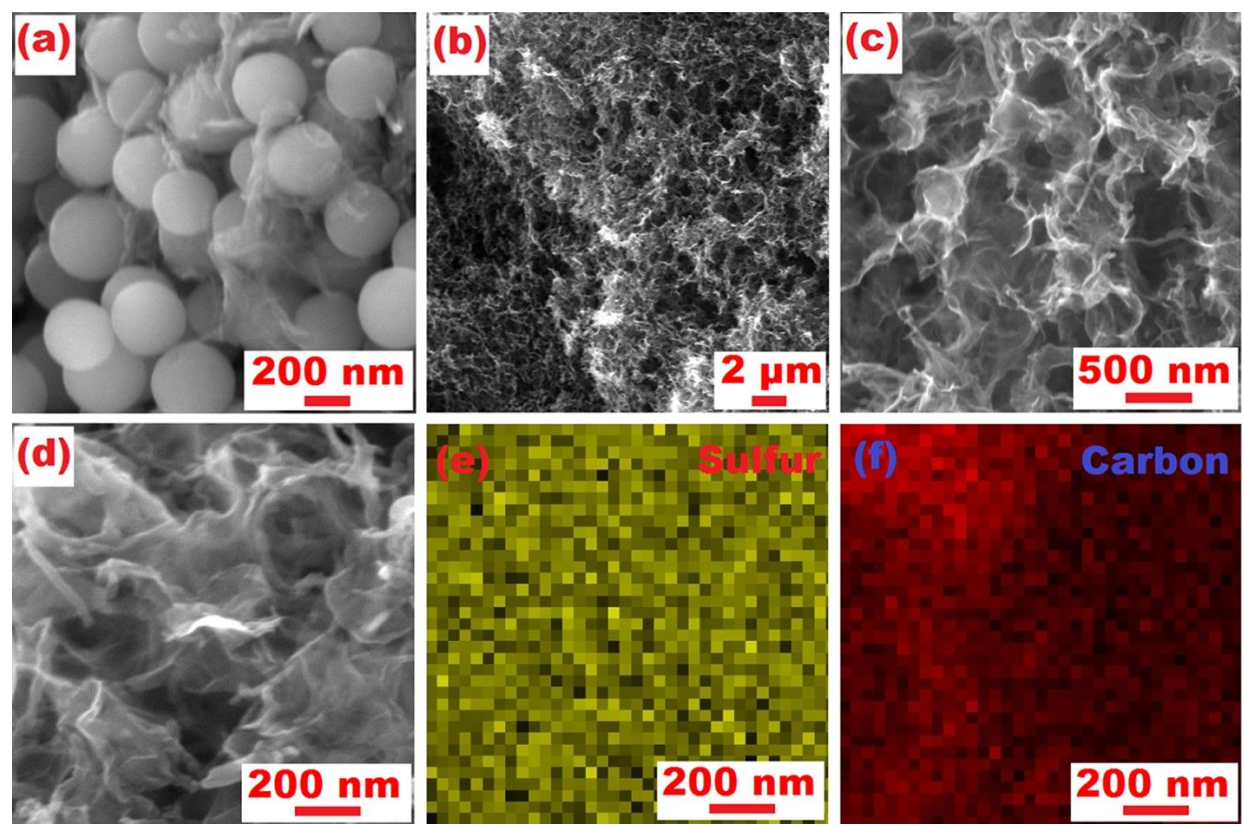

Figure 2: SEM images of (a)RGO@MWCNT@SiO sponding elemental maps of (e) sulfur and (f) carbon.
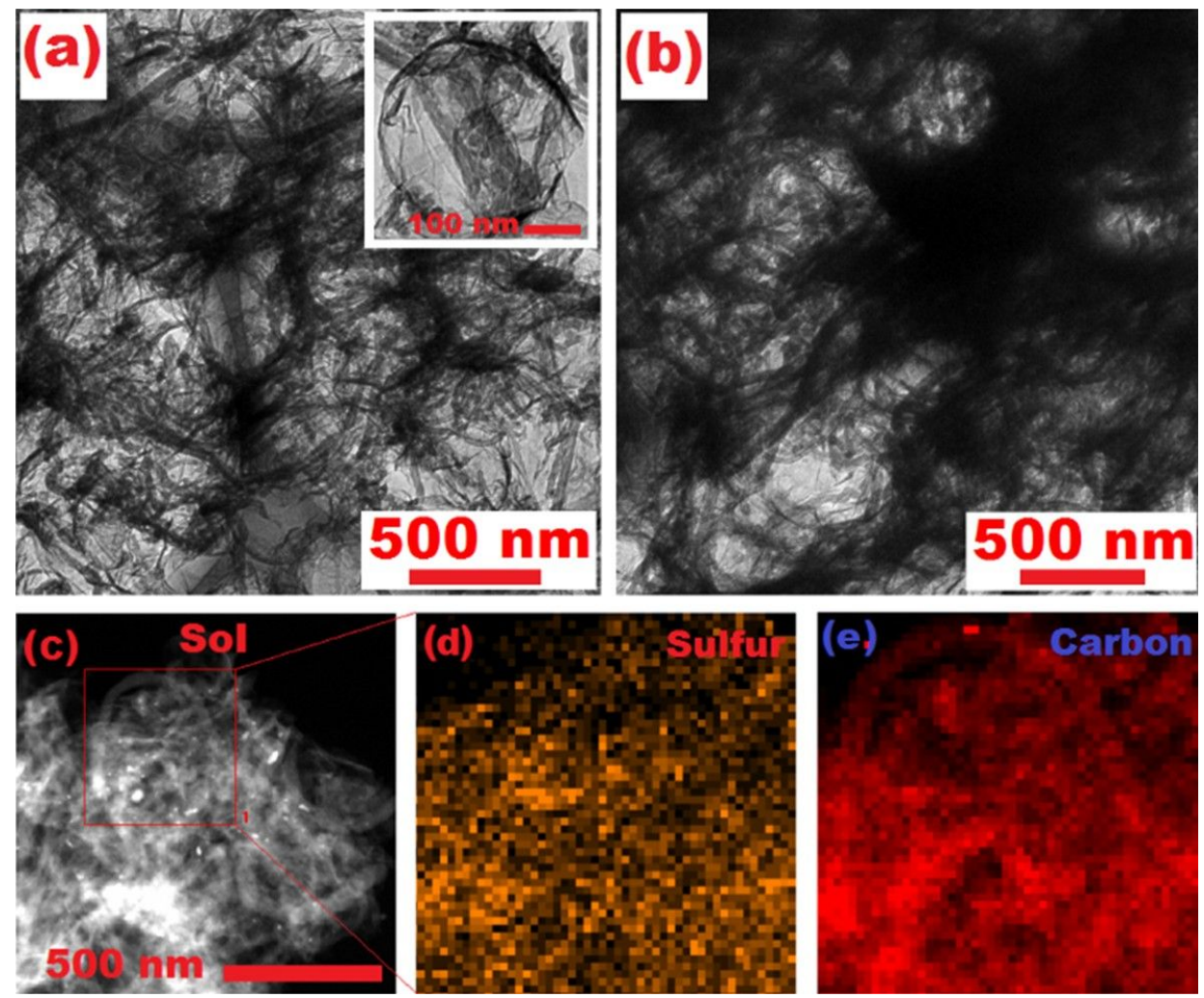

Figure 3: TEM images of (a) 3D-RGO@MWCNT with two different magnifications, (b) S-3D-RGO@MWCNT, (c-e) TEM mapping of (d) sulfur and

(e) carbon corresponding to the area outlined by the red square in the TEM image of (c). 
(a)

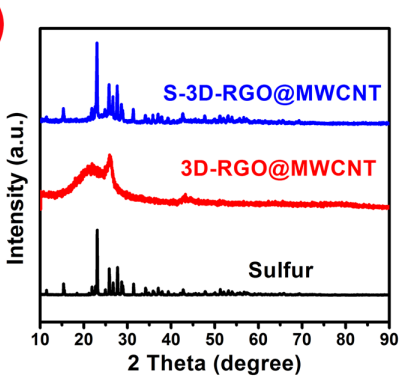

(d)

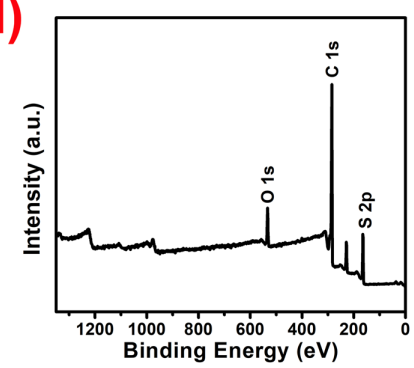

(b)

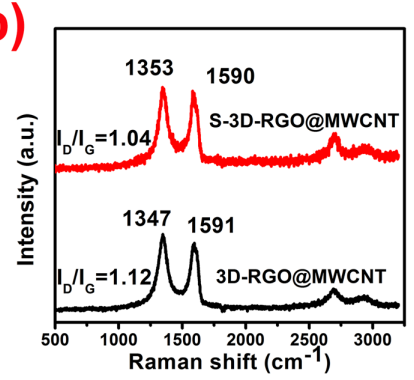

(e)

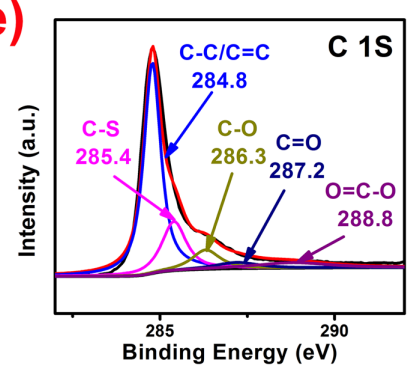

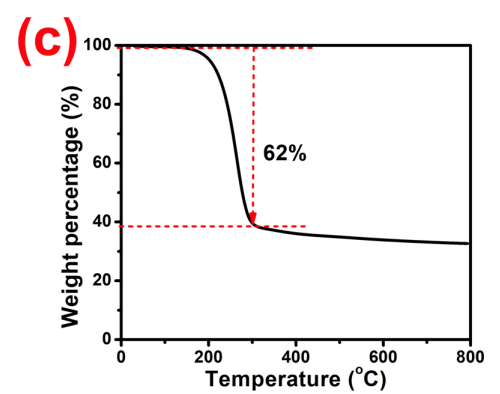

(f)

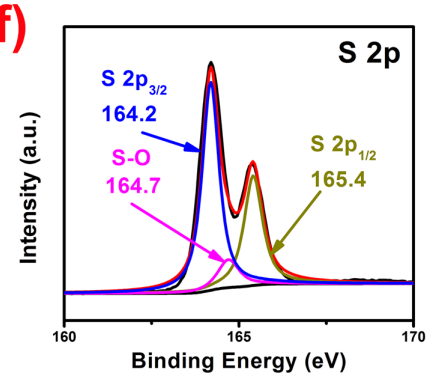

Figure 4: (a) XRD patterns of sulfur, 3D-RGO@MWCNT and S-3D-RGO@MWCNT; (b) Raman spectra of 3D-RGO@MWCNT and S-3DRGO@MWCNT; (c) TGA of S-3D-RGO@MWCNT; (d) The XPS survey spectrum of S-3D-RGO@MWCNT composite; high-resolution XPS spectra of (e) C 1s, (f) S 2p.

tion to the $\mathrm{C}-\mathrm{S}$ bonding, O-containing groups also help retain sulfur via $\mathrm{S}-\mathrm{O}$ bonding, as revealed by the peak located at $164.7 \mathrm{eV}$ in the $\mathrm{S} 2 \mathrm{p}$ spectrum (Figure 4e). The strong chemical bonding of $\mathrm{C}-\mathrm{S}$ and $\mathrm{S}-\mathrm{O}$ can immobilize sulfur and polysulfides within S-3D-RGO@MWCNT, reducing the shuttle effect and improving the cycling life of $\mathrm{Li}-\mathrm{S}$ batteries. The thermogravimetric analysis (TGA) analysis (Figure 4f) shows that the S-3D-RGO@MWCNT composite exhibits a very high weight loss $(62 \mathrm{wt} \%)$ between 30 and $300{ }^{\circ} \mathrm{C}$, confirming that a great amount of sulfur can be stored in the structure.

Figure 5 displays the first four CV cycles of S-3DRGO@MWCNT cathode at $0.1 \mathrm{mV} \cdot \mathrm{s}^{-1}$. During the cathodic cycle, the peaks around 2.30 and $2.05 \mathrm{~V}$ correspond to the transformation of elemental sulfur to long-chain polysulfides $\left(\mathrm{Li}_{2} \mathrm{~S}_{n}\right.$, $n \geq 4)$ and the reduction to short-chain polysulfides $(n<4)$, respectively. On the anodic side, the peak located at around $2.40 \mathrm{~V}$ corresponds to the oxidation of lithium polysulfides $\left(\mathrm{Li}_{2} \mathrm{~S}_{n}, n<4\right)$ and $\mathrm{Li}_{2} \mathrm{~S}$ to $\mathrm{Li}_{2} \mathrm{~S}_{8}$. It can be seen that during the cycling, the anodic peak shifts to a lower voltage, whereas the cathodic peaks remain almost unchanged. These results suggest the superior discharge stability of the S-3D-RGO@MWCNT cathode.

Figure 6a shows the charge and discharge voltage profiles of the S-3D-RGO@MWCNT cathode measured at 1C. The plateaus on the discharge $(2.30$ and $2.05 \mathrm{~V})$ and charge $(2.40 \mathrm{~V})$ profiles are consistent with those observed in the CV cycles. The voltage plateaus were preserved after 200 cycles, confirming

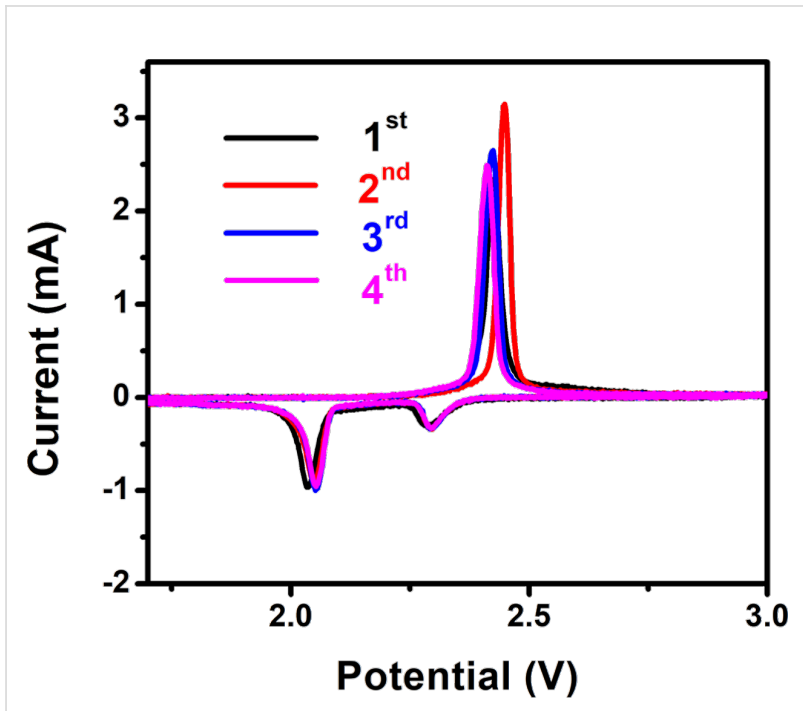

Figure 5: CV curves of the S-3D-RGO@MWCNT cathode at $0.1 \mathrm{mV} \cdot \mathrm{s}^{-1}$ in the first four cycles.

the excellent electrochemical stability of sulfur in the 3D structure of S-3D-RGO@MWCNT. The S-3D-RGO@MWCNT cathode exhibits an initial specific discharge capacity of $1102 \mathrm{mAh} \cdot \mathrm{g}^{-1}$ and a retained reversible capacity of $805 \mathrm{mAh} \cdot \mathrm{g}^{-1}$ after 200 cycles. This result concurs with that observed in the cycling performance of the S-3D-RGO@MWCNT cathode (Figure 6b). The discharge/charge coulombic efficiency was maintained at approximately $98 \%$ after 200 cycles. The cycling performance of S-3D-RGO@MWCNT indicates 


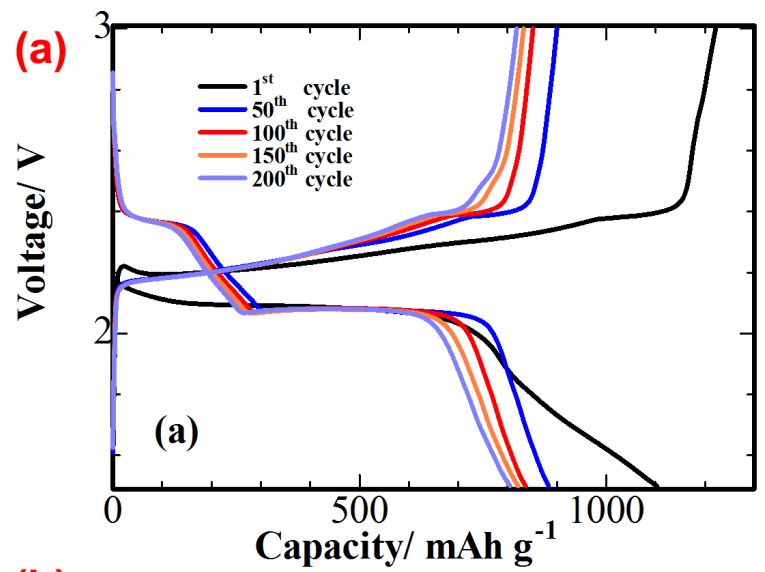

(b)

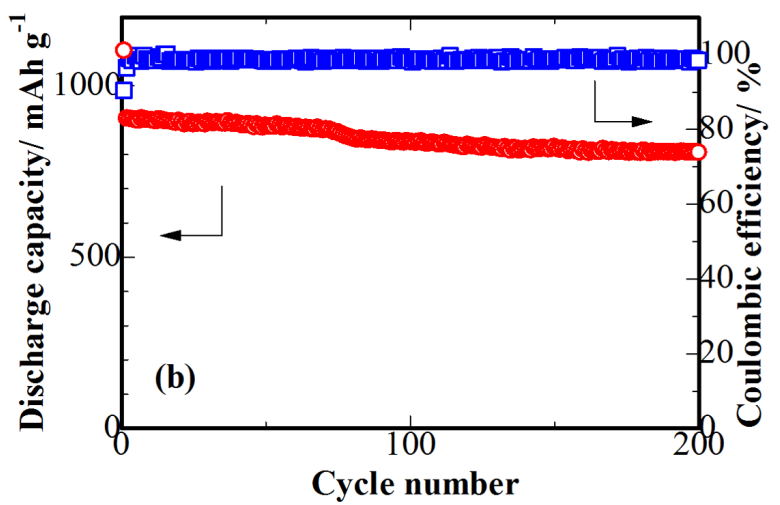

Figure 6: (a) CV measurement of the S-3D-RGO@MWCNT cathode (1st, 50th, 100th, 150th and 200th cycle) at 1C; (b) cycling performance of the S-3D-RGO@MWCNT cathode at $1 C$ for 200 cycles.

the efficient confinement of sulfur preventing the loss of active material through the shuttle effect.

Figure 7a reveals the charge-discharge voltage profiles of the batteries measured at various rates across the voltage range of 1.5 to $3.0 \mathrm{~V}$. A two-plateau behaviour of the discharge profiles was observed at all current densities, which is consistent with the $\mathrm{CV}$ curves peaks (Figure 5). As the current increases from $0.1 C$ to $2 C$, the polarization of the plateaus becomes higher, implying a slow decrease in the kinetic efficiency of the reaction process. This may have resulted from a weak influence of the current density on lower discharge plateau [27]. The rate capability of the S-3D-RGO@MWCNT cathode is examined in greater detail in Figure $7 \mathrm{~b}$. The impressive rate capability of the S-3D-RGO@MWCNT cathode was verified. Although a decrease of discharge capacity was observed when the current rate increases, a capacity of $770 \mathrm{mAh} \cdot \mathrm{g}^{-1}$ was still obtained at $2 \mathrm{C}$. When the current returned back to $0.1 C$, a capacity of $889 \mathrm{mAh} \cdot \mathrm{g}^{-1}$ was preserved. These observations reveal that the $3 \mathrm{D}$ structure upheld the excellent rate performance of the S-3DRGO@MWCNT cathode.
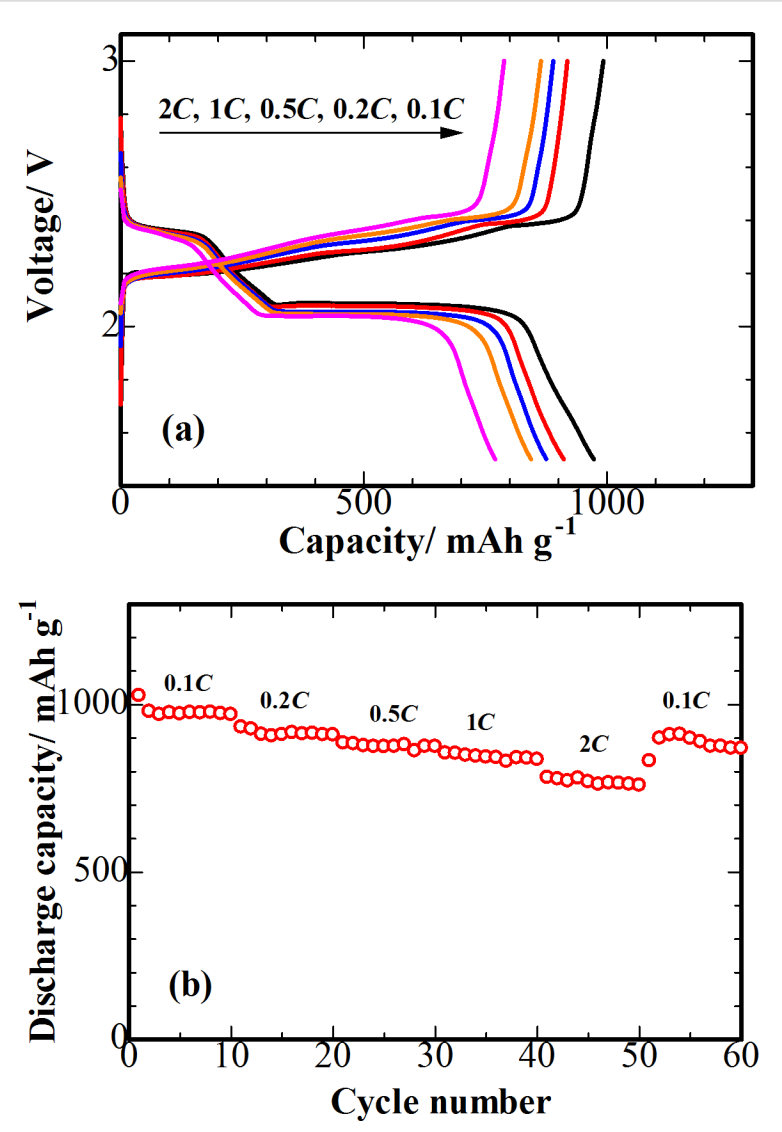

Figure 7: $(a, b)$ Specific capacity and rate performance of S-3DRGO@MWCNT cathode at different C-rate, ranging from $0.1 C$ to $2 C$.

The changes in the conductivity during cycling a Li-S battery equipped with the S-3D-RGO@MWCNT cathode, were investigated using electrochemical impedance spectroscopy (EIS). Figure 8 presents the Nyquist plots for the Li-S cell assessed before cycling, and after the 1 st and the 4 th cycle. In the high-

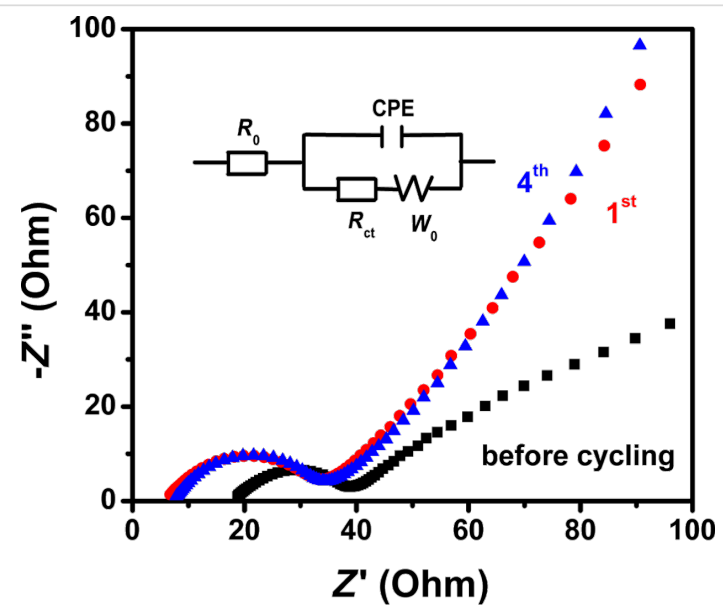

Figure 8: Nyquist plots of S-3D-RGO@MWCNT cathode and the equivalent circuit model (inset). 
frequency region the $x$-intercept is attributed to the contact resistance $\left(R_{0}\right)$, and the semicircle is attributed to the chargetransfer resistance $\left(R_{\mathrm{ct}}\right)$ at the electrode/electrolyte interface. Finally, the inclined slope in the low-frequency region is associated with the Warburg impedance (W) [28], which correlates to the $\mathrm{Li}^{+}$transportation process. Notably, there is a significant shift in the impedance curves before and after cycling. The primary reason for the decrease in the contact resistance after the initial cycle may be the redispersion of sulfur. The significant shift in the Warburg element indicates an improved $\mathrm{Li}^{+}$diffusivity [29]. $R_{\mathrm{ct}}$ increases slightly, then stabilizes after the initial cycle, which agrees with the cyclability data. The fitted values of $R_{0}$ and $R_{\mathrm{ct}}$ for the S-3D-RGO@MWCNT cathode are tabulated in Table 1. The impedance curves of the $1 \mathrm{st}$ and the 4 th cycle are similar and become very stable, indicating the enhanced electrochemical performance of the S-3DRGO@MWCNT cathode, which can be attributed to its 3D porous lattice matrix structure and the facilitation of rapid $\mathrm{Li}^{+}$ diffusion.

\begin{tabular}{|c|c|c|}
\hline cycle number & $R_{0}(\Omega)$ & $R_{\mathrm{ct}}(\Omega)$ \\
\hline before cycling & 18.08 & 22.11 \\
\hline 1st cycle & 6.32 & 26.4 \\
\hline 4th cycle & 7.62 & 26.49 \\
\hline
\end{tabular}

\section{Conclusion}

In summary, a unique S-3D-RGO@MWCNT composite, consisting of porous spherical RGO integrated within a MWCNT lattice matrix, was successfully synthesized. The as-prepared S-3D-RGO@MWCNT cathode exhibited a very good electrochemical performance and cycle stability. This can be attributed to i) the conductive network inherently found in the RGO sheets and MWCNTs, which ensured efficient charge transfer within the cathode, ii) the $3 \mathrm{D}$ porous spherical RGO possessing a high surface area and pore volume to accommodate a high sulfur content; and iii) the interconnected pores in the spherical RGO and the lattice matrix formed by MWCNTs, which act as polysulfide reservoirs to alleviate the shuttle effect, and thereby improving the cycling stability of the battery. Lastly, the interconnected pores ensured the rapid $\mathrm{Li}^{+}$diffusion during the discharge/charge process, and therefore were beneficial for reducing the internal resistance and improving the electrochemical properties.

\section{Experimental}

\section{Synthesis of 3D-RGO@MWCNT composite}

The synthesis of 3D-RGO@MWCNT composite consists of the following steps: i) the preparation of monodispersed $\mathrm{SiO}_{2}$ spherical particles using Stober's method [30]; ii) the preparation of graphene oxide (GO) using Hummers method [31]; iii) the incorporation of MWCNTs; iv) the reduction of GO, and v) $\mathrm{SiO}_{2}$ etching by HF. Firstly, monodispersed $\mathrm{SiO}_{2}$ spheres with diameters of 200-300 nm were prepared. After washing and drying, the $\mathrm{SiO}_{2}$ sphere particles was subsequently dispersed in DI water at a concentration of $50 \mathrm{mg} \cdot \mathrm{mL}^{-1}$ (suspension A). Secondly, the GO from Hummer's method was dispersed into DI water at a concentration of $2 \mathrm{mg} \cdot \mathrm{mL}^{-1}$, and subsequently mixed with a $2 \mathrm{mg} \cdot \mathrm{mL}^{-1} \mathrm{MWCNT}$ suspension at a mass ratio of 1:1. The as-prepared GO@MWCNT suspension was afterwards mixed with suspension $\mathrm{A}$ and volumetric ratio of 3:1 resulting in $\mathrm{GO} @ \mathrm{MWCNT} @ \mathrm{SiO}_{2}$ (suspension B). After sonicated for $30 \mathrm{~min}$, sodium erythorbate was added to suspension $\mathrm{B}$ and heated in an oil bath for $2 \mathrm{~h}$. The sodium erythorbate was removed by washing with DI water, while $\mathrm{SiO}_{2}$ was etched away by subsequent soaking in $10 \% \mathrm{HF}$ for a week. Lastly, HF was also rinsed out with DI water and ethanol. After drying the compound at $60{ }^{\circ} \mathrm{C}$ for $12 \mathrm{~h}$, the 3D-RGO@MWCNT composite was obtained.

\section{Synthesis of S-3D-RGO@MWCNT composite and S-cathode}

The as-prepared 3D-RGO@MWCNT was mixed with nanosulfur at a mass ratio of 1:2. The resulting sample was heated at $155^{\circ} \mathrm{C}$ for $12 \mathrm{~h}$ in a nitrogen-filled autoclave producing the S-3D-RGO@MWCNT composite. The cathode was fabricated by coating a slurry of S-3D-RGO@MWCNT, polyvinylidene fluoride (PVDF) and carbon black (mass ratio 8:1:1) on a carbon-coated Al foil.

\section{Materials characterization}

$\mathrm{X}$-ray diffraction (XRD) patterns of the as-prepared 3D-RGO@MWCNT composite were obtained using XRD (SmartLab, Rigaku Corporation) with $\mathrm{Cu} \mathrm{Ka}$ radiation. X-ray photoelectron spectroscopy (XPS, Shimadzy Axis Ultra) was applied to investigate the chemical valence states and compositions of the sample. Scanning electron microscopy (SEM, Hitachi S4800) and high-resolution transmission electron microscopy (HRTEM, JEOL JEM-2100F) images were used for investigating surface topology. The content of sulfur in the S-3D-RGO@MWCNT composite was confirmed using thermogravimetric analysis (TGA, SHIMADZU DTG-60) in Ar atmosphere. Raman spectra were recorded on Raman spectrometer (Raman, Renishaw) using $532 \mathrm{~nm}$ radiation.

\section{Electrochemical measurements}

CR2025 coin batteries were assembled using S-3DRGO@MWCNT as the cathode, 1 M lithium bistrifluoromethanesulfonimide and $0.1 \mathrm{M} \mathrm{LiNO}_{3}$ in a mixed solution of DME-DOL (1:1 by volume) as electrolyte, a Li foil as anode, 
and a Celgard 2300 membrane as separator. The cycling performances of the Li-S battery was investigated using a battery testing station (Neware, Shenzhen) in potential range of 1.5-3.0 V. The electrochemical workstation (Princeton, VersaSTAT 4) was used to evaluate cyclic voltammetry (CV) also in a potential range of 1.5-3.0 V. Electrochemical impedance spectroscopy (EIS) was carried out in the frequency range from $10^{-2}$ to $10^{5} \mathrm{~Hz}$.

\section{Supporting Information}

\section{Supporting Information File 1}

Additional experimental data.

[https://www.beilstein-journals.org/bjnano/content/

supplementary/2190-4286-10-52-S1.pdf]

\section{Acknowledgements}

This work was supported by the Program for the Outstanding Young Talents of Hebei Province; the Science Research Foundation for Selected Overseas Chinese Scholars, Ministry of Human Resources and Social Security of China [grant number CG2015003002]; Cultivation project of National Engineering Technology Center [Grant No. 2017B090903008].

\section{References}

1. He, J.; Chen, Y.; Lv, W.; Wen, K.; Li, P.; Wang, Z.; Zhang, W.; Qin, W.; He, W. ACS Energy Lett. 2016, 1, 16-20. doi:10.1021/acsenergylett.6b00015

2. Mahmood, N.; Hou, Y. Adv. Sci. 2014, 1, 1400012-1400031. doi:10.1002/advs.201400012

3. Zheng, S.; Wen, Y.; Zhu, Y.; Han, Z.; Wang, J.; Yang, J.; Wang, C. Adv. Energy Mater. 2014, 4, 1400482-1400490. doi:10.1002/aenm.201400482

4. He, J.; Chen, Y.; Lv, W.; Wen, K.; Li, P.; Qi, F.; Wang, Z.; Zhang, W.; Li, Y.; Qin, W.; He, W. J. Power Sources 2016, 327, 474-480. doi:10.1016/j.jpowsour.2016.07.088

5. Barchasz, C.; Molton, F.; Duboc, C.; Leprêtre, J.-C.; Patoux, S.; Alloin, F. Anal. Chem. (Washington, DC, U. S.) 2012, 84, 3973-3980. doi:10.1021/ac2032244

6. Mikhaylik, Y. V.; Akridge, J. R. J. Electrochem. Soc. 2003, 150, A306-A311. doi:10.1149/1.1545452

7. Manthiram, A.; Fu, Y.; Chung, S.-H.; Zu, C.; Su, Y.-S. Chem. Rev. 2014, 114, 11751-11787. doi:10.1021/cr500062v

8. Guo, Z.; Nie, H.; Yang, Z.; Hua, W.; Ruan, C.; Chan, D.; Ge, M.; Chen, X.; Huang, S. Adv. Sci. 2018, 5, 1800026-1800033. doi:10.1002/advs.201800026

9. Rehman, S.; Gu, X.; Khan, K.; Mahmood, N.; Yang, W.; Huang, X.; Guo, S.; Hou, Y. Adv. Energy Mater. 2016, 6, 1502518-1502525. doi:10.1002/aenm.201502518

10. He, J.; Lv, W.; Chen, Y.; Xiong, J.; Wen, K.; Xu, C.; Zhang, W.; Li, Y.; Qin, W.; He, W. J. Mater. Chem. A 2018, 6, 10466-10473. doi:10.1039/c8ta02434k

11. Mahmood, N.; Zhang, C.; Yin, H.; Hou, Y. J. Mater. Chem. A 2014, 2 , 15-32. doi:10.1039/c3ta13033a
12. He, J.; Chen, Y.; Manthiram, A. Energy Environ. Sci. 2018, 11 2560-2568. doi:10.1039/c8ee00893k

13. Huang, J.-Q.; Wang, Z.; Xu, Z.-L.; Chong, W. G.; Qin, X.; Wang, X.; Kim, J.-K. ACS Appl. Mater. Interfaces 2016, 8, 28663-28670. doi:10.1021/acsami.6b10032

14. Gu, X.; Tong, C.-j.; Wen, B.; Liu, L.-m.; Lai, C.; Zhang, S. Electrochim. Acta 2016, 196, 369-376. doi:10.1016/j.electacta.2016.03.018

15. Wang, S.; Yang, Z.; Zhang, H.; Tan, H.; Yu, J.; Wu, J. Electrochim. Acta 2013, 106, 307-311. doi:10.1016/j.electacta.2013.05.083

16. Qu, Q.; Gao, T.; Zheng, H.; Wang, Y.; Li, X.; Li, X.; Chen, J.; Han, Y.; Shao, J.; Zheng, H. Adv. Mater. Interfaces 2015, 2, 1500048-1500054. doi:10.1002/admi.201500048

17. Gu, X.; Wang, Y.; Lai, C.; Quu, J.; Li, S.; Hou, Y.; Martens, W.; Mahmood, N.; Zhang, S. Nano Res. 2015, 8, 129-139. doi:10.1007/s12274-014-0601-1

18. Li, Z.; Zhang, J.; Lou, X. W. D. Angew. Chem., Int. Ed. 2015, 54, 12886-12890. doi:10.1002/anie.201506972

19. Gnana kumar, G.; Chung, S.-H.; Raj kumar, T.; Manthiram, A. ACS Appl. Mater. Interfaces 2018, 10, 20627-20634. doi:10.1021/acsami.8b06054

20. He, J.; Chen, Y.; Lv, W.; Wen, K.; Xu, C.; Zhang, W.; Li, Y.; Qin, W.; He, W. ACS Nano 2016, 10, 10981-10987. doi:10.1021/acsnano.6b05696

21. He, J.; Chen, Y.; Manthiram, A. Adv. Mater. (Weinheim, Ger.) 2017, 29 1702707. doi:10.1002/adma.201702707

22. He, J.; Chen, Y.; Manthiram, A. iScience 2018, 4, 36-43. doi:10.1016/j.isci.2018.05.005

23. Zhou, W.; Wang, C.; Zhang, Q.; Abruña, H. D.; He, Y.; Wang, J.; Mao, S. X.; Xiao, X. Adv. Energy Mater. 2015, 5, 1401752-1401759. doi:10.1002/aenm.201401752

24. He, J.; Chen, Y.; Li, P.; Fu, F.; Wang, Z.; Zhang, W. J. Mater. Chem. A 2015, 3, 18605-18610. doi:10.1039/c5ta04445f

25. He, J.; Chen, Y.; Lv, W.; Wen, K.; Xu, C.; Zhang, W.; Qin, W.; He, W ACS Energy Lett. 2016, 1, 820-826. doi:10.1021/acsenergylett.6b00272

26. Zhang, Y.; Sun, L.; Li, H.; Tan, T.; Li, J. J. Alloys Compd. 2018, 739, 290-297. doi:10.1016/j.jallcom.2017.12.294

27. Qian, W.; Gao, Q.; Zhang, H.; Tian, W.; Li, Z.; Tan, Y. Electrochim. Acta 2017, 235, 32-41. doi:10.1016/j.electacta.2017.03.063

28. Martha, S. K.; Markovsky, B.; Grinblat, J.; Gofer, Y.; Haik, O.; Zinigrad, E.; Aurbach, D.; Drezen, T.; Wang, D.; Deghenghi, G.; Exnar, I. J. Electrochem. Soc. 2009, 156, A541-A552. doi:10.1149/1.3125765

29. Zhang, Y.; Zhao, Y.; Bakenov, Z.; Tuiyebayeva, M.; Konarov, A.; Chen, P. Electrochim. Acta 2014, 143, 49-55. doi:10.1016/j.electacta.2014.07.148

30. Philipse, A. P. J. Mater. Sci. Lett. 1989, 8, 1371-1373. doi:10.1007/bf00720190

31. Wang, X.; Lu, C.; Peng, H.; Zhang, X.; Wang, Z.; Wang, G. J. Power Sources 2016, 324, 188-198. doi:10.1016/j.jpowsour.2016.05.085 


\section{License and Terms}

This is an Open Access article under the terms of the Creative Commons Attribution License (http://creativecommons.org/licenses/by/4.0). Please note that the reuse, redistribution and reproduction in particular requires that the authors and source are credited.

The license is subject to the Beilstein Journal of Nanotechnology terms and conditions:

(https://www.beilstein-journals.org/bjnano)

The definitive version of this article is the electronic one which can be found at:

doi:10.3762/bjnano.10.52 